\title{
Coastal influences on pollution transport
}

\author{
D. Peake, H. Dacre \& J. Methven \\ Department of Meteorology, Reading University, UK
}

\begin{abstract}
The ventilation of pollutants from the boundary layer into the free troposphere is an important process in controlling regional air quality. Coastal outflow is the horizontal ventilation of pollutants across a coastline from a layer within the continental boundary layer to above the marine boundary layer. It has been shown using the Met Office Unified Model that the ventilation by coastal outflow occurs with a similar order of magnitude to ventilation by convection, and that it possesses a diurnal cycle induced by the boundary layer height cycle over land. Pollutants with short lifetimes (typically several hours) exhibit the greatest diurnal variability in export by coastal outflow. Ventilation by coastal outflow by pollutants with longer lifetimes are less dependent on the boundary layer height over land and more dependent on the large scale cross-coastal wind strength. A simple model developed to simulate coastal outflow shows that increasing the pollutant lifetime, wind speed or convective boundary layer height increases export of tracer by coastal outflow. Above a threshold windspeed, coastal outflow is reduced due to tracer being exported across a coastline before being able to be mixed to a height greater than the marine boundary layer. Convection slightly decreases export by coastal outflow, although this effect is small.
\end{abstract}

Keywords: coastal outflow, pollution, modelling, coasts, tracer, ventilation, export boundary layer.

\section{Introduction}

The vertical ventilation of pollutants from the boundary layer to the free troposphere through convection and frontal mechanisms has a significant impact on regional air quality [1,2] and has been extensively studied [3-5]. The prospect of horizontal ventilation across a discontinuity in boundary layer height, such as one present at a coastline, has received relatively little attention [6]. During the 


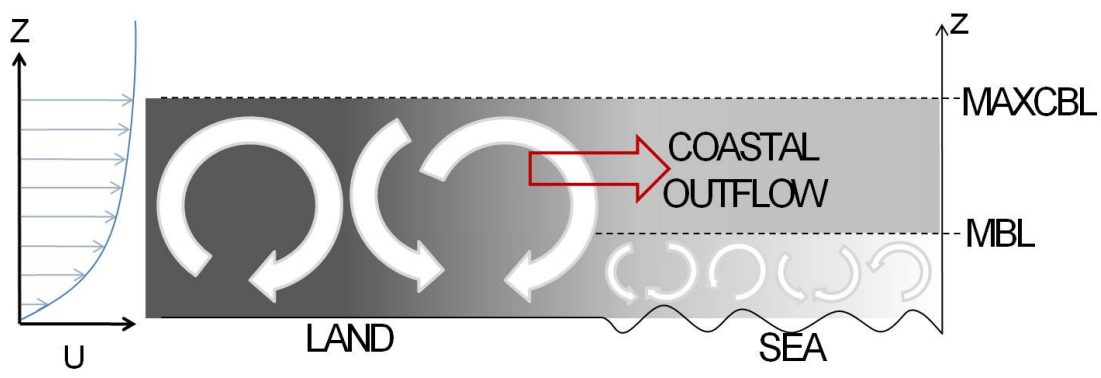

Figure 1: Schematic of coastal outflow. A logarithmic wind profile is shown on the left. Large circular arrows represent boundary layer scale turbulent eddies, grey shading represents pollution. MBL represents the height of the marine boundary layer away from the coast, MAXCBL represents the maximum convective boundary layer height. Deposition in the marine boundary layer is assumed.

daytime the convective boundary layer (CBL) over the land typically grows to a greater depth than the marine boundary layer (MBL). Thus pollutants advected horizontally across a coastline within the CBL can be transported above the MBL through coastal outflow (Figure 1). This layer of air above the MBL can become decoupled from the surface, and is subject to higher wind speeds and negligible deposition, enabling more efficient long-range transport than within the MBL. Verma [7] and Raman [8] show that pollutants are frequently observed in layers above the top of the MBL. This study uses the Met Office Unified Model with passive tracers to quantify coastal outflow and investigate the meteorological processes that control it.

\section{Experiment setup}

The Met Office Unified Model (UM), version 6.1, has been used in this study. It is a non-hydrostatic fully-compressible model which runs the Navier-Stokes equations forward in time using a semi-implicit and semi-lagrangian numerical scheme across staggered grids in both the horizontal (Arakawa-C grid) and vertical (Charney-Phillips grid). The UM model is documented by [9] and runs the new dynamics regime [10].

The UM is run in Limited Area Mode (LAM) over the east coast of the US, chosen to include a large part of the International Consortium for Atmospheric Research on Transport and Transformation (ICARTT) field campaign domain for observational verification, and is shown in Figure 2. The LAM simulation starts at $0000 \mathrm{Z}$ on $13 / 07 / 04$ and is run for 27 days with a horizontal resolution of $0.11^{\circ}$ $(12 \mathrm{~km})$ and has 38 terrain-following model levels in the vertical, of which 10 levels are situated in the lowest $2 \mathrm{~km}$ above ground level. The model run is initialised 


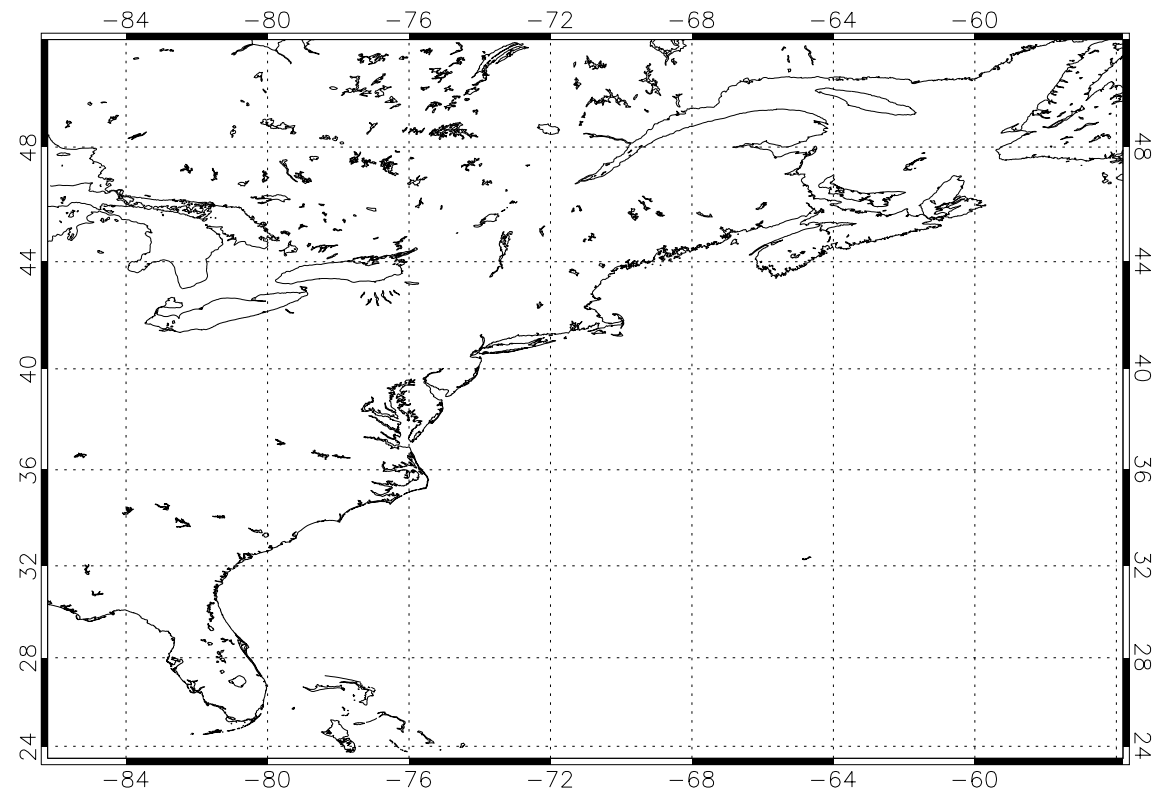

Figure 2: Map of the limited area domain used in the UM in this study, with latitudes and longitudes included for reference.

using a global analysis from the European Center for Medium-Range Weather Forecasts' (ECMWF) archive, and its boundaries are forced every six hours with data from ECMWF global re-analyses.

Pollution transport is modelled using four passive tracers, two of which have e-folding lifetimes of 3 and 24 hours. The tracers are passive in that they undergo no chemical transformation other than an exponential decay of the specified timescale. The tracers are initialised and emitted (with constant source rate) in the lowest model level over land only. For each lifetime, one tracer is transported by the turbulent mixing parameterisation and advection schemes, the other by turbulent mixing, advection and convection schemes. Although the advective and convective processes are not additive, this will allow the relative importance of convection upon coastal outflow to be ascertained. Any external air mass advected into the domain is assumed to have a tracer mixing ratio of $0 \mathrm{~kg} / \mathrm{kg}$.

The model domain is then split into six regions (boxes) for analysis, the 'boundary', 'residual' and 'free tropospheric' layers over the land and sea respectively, shown in Figure 2. Tracer that has been exported from the continent by coastal outflow is located in box $\mathrm{M}_{4}$, which extends from the top of the marine boundary layer to the top of the MAXCBL, the maximum height the convective boundary layer reaches during its diurnal cycle. 


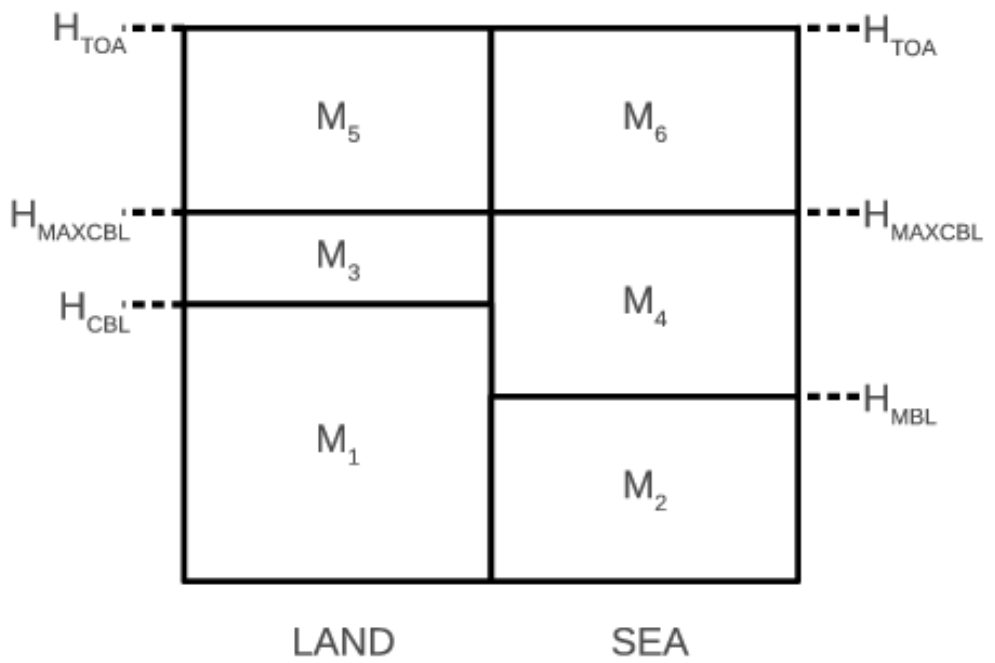

Figure 3: Splitting the domain into six regions: boundary $\left(\mathrm{M}_{1}, \mathrm{M}_{2}\right)$, residual $\left(\mathrm{M}_{3}, \mathrm{M}_{4}\right)$ and free tropospheric layers $\left(\mathrm{M}_{5}, \mathrm{M}_{6}\right)$ over land and sea respectively. $\mathrm{H}_{C B L}$ and $\mathrm{H}_{M B L}$ represent the heights of the convective and marine boundary layers. $\mathrm{H}_{M A X C B L}$ represents the maximum height the convective boundary layer reaches through its diurnal cycle. $\mathrm{H}_{T O A}$ represents the height at model top. Each box contains a mass of tracer $\mathrm{M}_{x}$, boxes 1, 3 and 5 are placed over land, boxes 2, 4 and 6 over the sea, with the coast in between. Tracer undergoing coastal outflow is horizontally advected to box $\mathrm{M}_{4}$.

\section{Results}

\subsection{Diurnal cycle}

Figure 4 shows a composite of the diurnal cycle of tracer contained within box $\mathrm{M}_{4}$, i.e. exported through coastal outflow, in the UM model run for the 3- and 24-hour tracers passed through the advection, convection and turbulent mixing schemes. 14 days are averaged together to generate an average diurnal cycle (solid line) and day-to-day variability (grey shading) of coastal outflow. Approximately $5 \%$ of the total domain 3-hour tracer (Figure 4a) is exported in box $M_{4}$ by coastal outflow, with a maximum occuring at $5 \mathrm{pm}$ local time (LT) and a minimum at 9am LT. Due to the short lifetime of the tracer, coastal outflow can only occur when the depth of the CBL is greater than that of the MBL, and so the maximum occurs in the late afternoon when the CBL has grown deep enough to enable the export of pollutants at a high enough altitude to be present above the MBL. Consequently the minimum occurs in the late morning when tracer emitted at the surface is trapped by a shallow CBL for the nighttime, leading to little coastal outflow due to tracer decaying quickly in the residual layer. 
Due to its longer lifetime, a greater proportion (12\%) of the 24-hour lifetime tracer is exported through coastal outflow (Figure 4b) compared to the 3-hour tracer. Due to its slower decay, coastal outflow can continue to occur during the night as a greater concentration of tracer is present in the residual layer over land. As such, the 24-hour tracer exhibits little diurnal variability and undergoes continuous export by coastal outflow.

The percentages of 3- and 24-hour tracer that undergo coastal outflow are of the same order of magnitude as that which is transported above the MAXCBL by resolved ascent and/or convection in the model, with $6 \%$ and $15 \%$ of the total domain tracer mass respectively located in box $\mathrm{M}_{5}$. The differences in the export percentage when tracer is included in the convection scheme are negligible (not shown). Convection increases boundary layer ventilation, by decreasing the mass of tracer within boxes $\mathrm{M}_{1}$ and $\mathrm{M}_{3}$ and transporting it to free-tropospheric box $\mathrm{M}_{5}$. This leads to a reduction in coastal outflow. For the 3- and 24-hour tracers reductions of $0.1 \%$ and $0.5 \%$ occured, which are small when compared to their magnitudes (5\% and 12\%). Convection thus has little effect on coastal outflow.

\subsection{Day-to-day variability}

Figure 5 shows the percentage of 3- and 24-hour tracer that is exported by coastal outflow across the whole domain as a time series for the first 17 days of the model run (entire model run time series not shown for clarity reasons). Note that for all timeseries plots, the first two days should be regarded as spin up, when high concentrations of tracer were initialised in the lowest model level over land leading to an unrealistic picture of tracer distribution during this time. The 3hour tracer export exhibits a clear diurnal cycle, whereas the 24-hour tracer does not, consistent with Figure 4. The 24-hour tracer exhibits a strong day-to-day variability that can lead to a near doubling of tracer export at some times $(17 \%$ on 16th, 17th, 21st July) compared to others (9\% on 25th, 26th). The 3-hour tracer possesses less day-to-day variability due to its shorter lifetime.

The day-to-day variability could be controlled by the variation in day-to-day maximum convective boundary layer height or by horizontal cross-coastal wind speed. These factors are investigated in Figure 6. Figure 6a shows the domain average zonal wind speed at $850 \mathrm{~m}$ above ground level, a typical height at which coastal outflow occurs at the coast. When a 24 hour lag is taken into account, there is a strong correlation $(\mathrm{r}=0.88)$ between the $850 \mathrm{~m}$ wind field and proportion of 24-hour tracer exported by coastal outflow, accounting for $77 \%$ of variability in export by coastal outflow. The 90th percentile (chosen to remove outliers) of convective boundary layer height has a maximum that varies by less than $25 \%$ from day-to-day (Figure $6 \mathrm{~b})$ and accounts for $8 \%(\mathrm{r}=0.28)$ the day-to-day variability in modelled coastal outflow. Thus the dominant mechanism for controlling coastal outflow is the large-scale wind speed. 
(a)
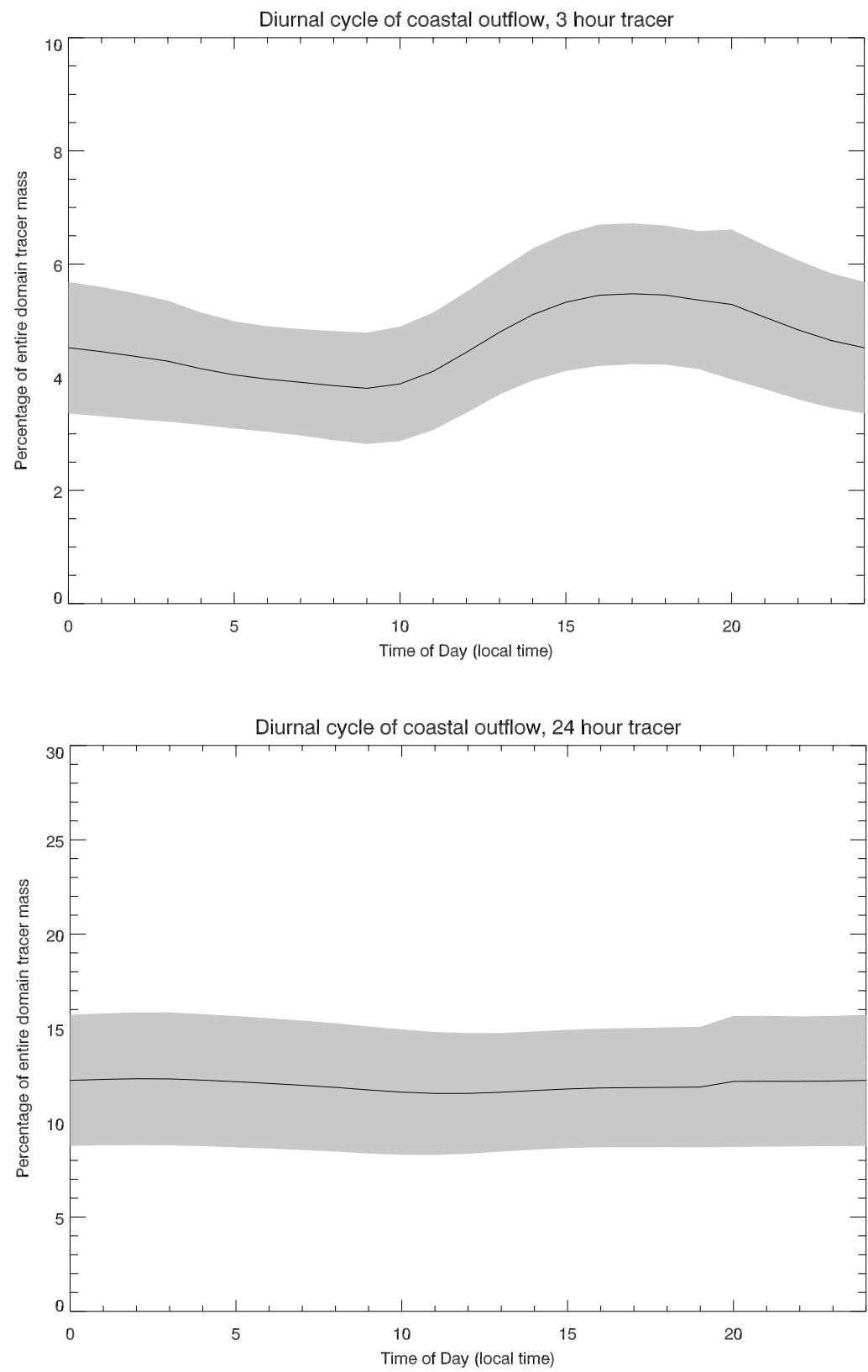

Figure 4: Calculated from the UM, panels a and $b$ show the proportion of total domain tracer mass in box $\mathrm{M}_{4}$ (exported by coastal outflow), for the 3and 24-hour life time tracers respectively. The grey shading represents one standard deviation in coastal outflow per hour of day. 


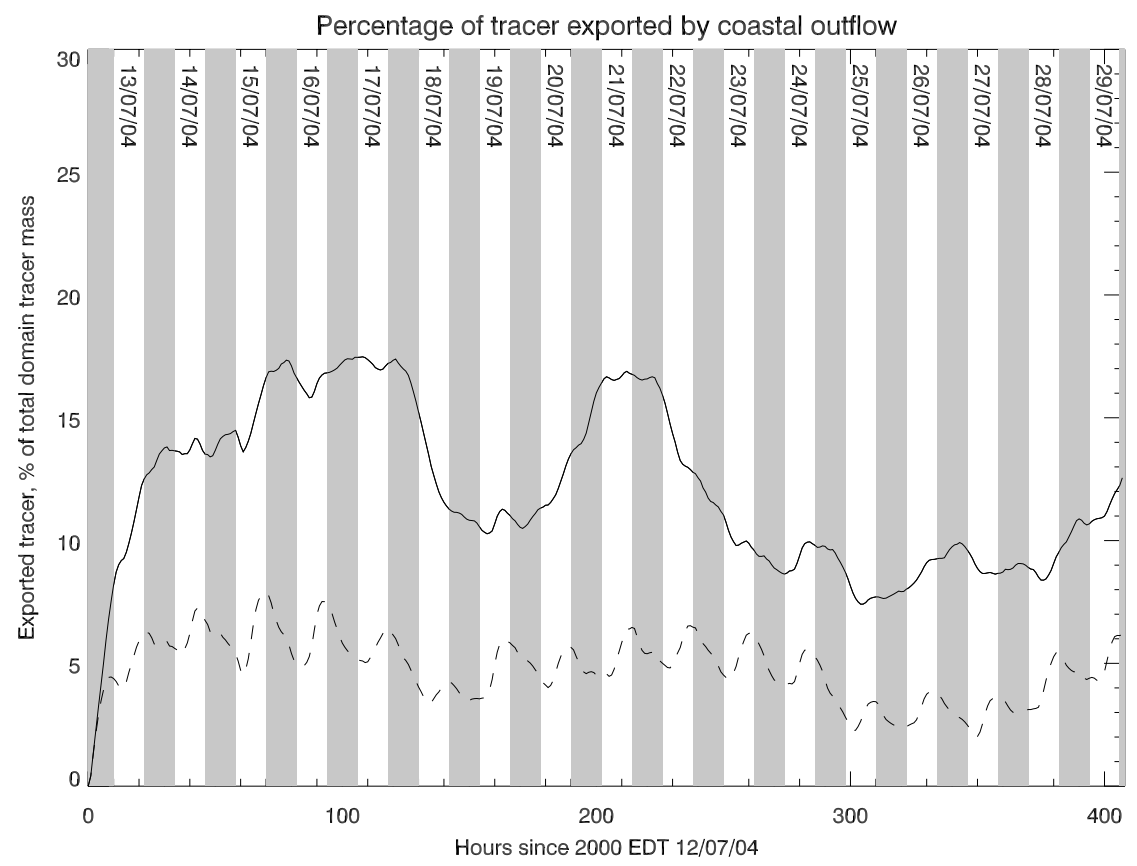

Figure 5: Percentage of total domain 3-hour (dashed line) and 24-hour (solid line) tracer exported by coastal outflow from 13/07/04 to 29/07/04. Grey shaded areas represent 6pm-6am. Model spin up occurs during the first two days, hence exported tracer initially starting at zero.

\subsection{Simulating variability}

A 2D 'box model' has been constructed to base coastal outflow on as few variables as possible and simulate its observed diurnal cycle and variability. The model tests the sensitivity of coastal outflow to 3 variables: wind speed, maximum boundary layer height and pollutant lifetime. The model consists of six boxes, in which pollutants are assumed to be well mixed, of the same structure as illustrated in Figure 2. The convective boundary layer height is assumed to be sinusoidal with time, the maximum MAXCBL occuring at noon and minimum of $50 \mathrm{~m}$ at midnight. A wind speed, $U m s^{-1}$, is assumed to advect directly from land to sea, the width of the land boxes is prescribed to be $L$ meters, and width of the sea boxes infinitely long to ensure no tracer exits the domain. The proportion of tracer advected from land to sea is $U / L s^{-1}$. Passive tracers with specified lifetimes ranging from minutes to months are emitted in box $\mathrm{M}_{1}$. There is no resolved ascent, convection or entrainment within this model, therefore no tracer enters boxes $\mathbf{M}_{5}$ or $\mathbf{M}_{6}$.

The model replicate the UM simulated diurnal cycle in coastal outflow (not shown). Figure 7 shows the average percentage of tracer exported each 


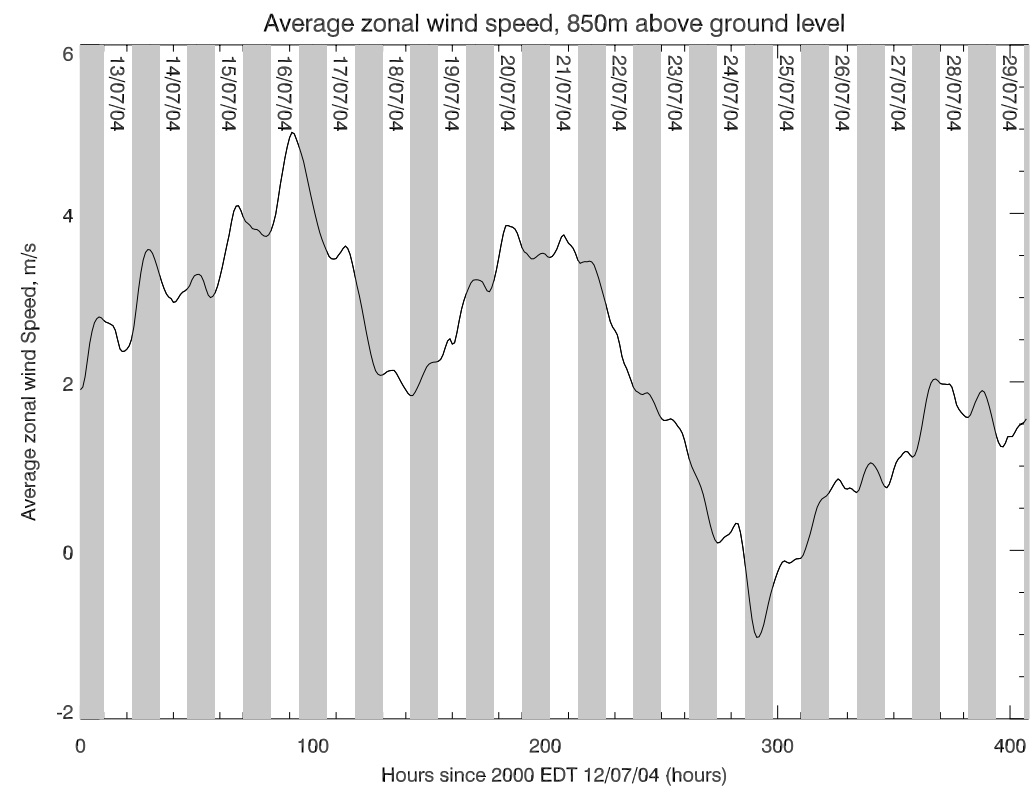

(a)

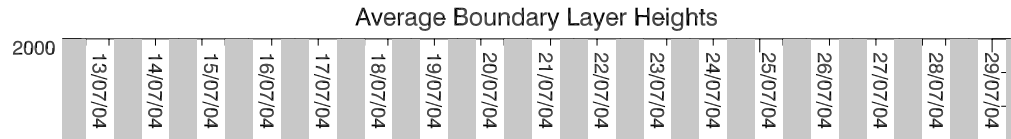

(b)

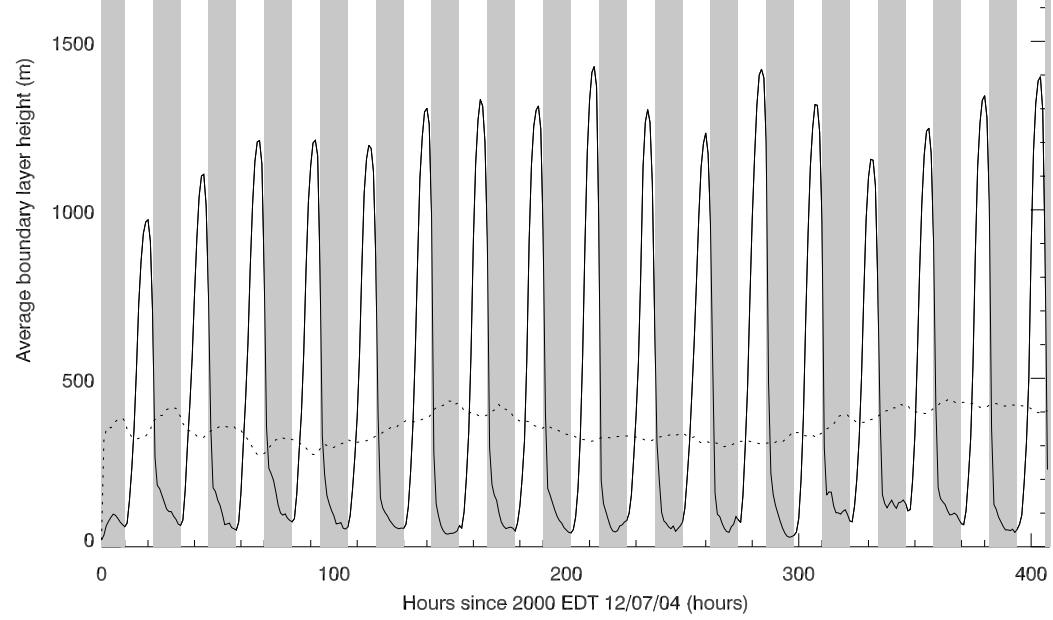

Figure 6: UM simulated time series of (a) domain average zonal wind speed and (b) 90th percentile (chosen to remove outliers) of domain average boundary layer heights over the land (solid line) and sea (dashed line). Grey shaded areas represent 6pm-6am. Model spin up occurs during the first two days. 


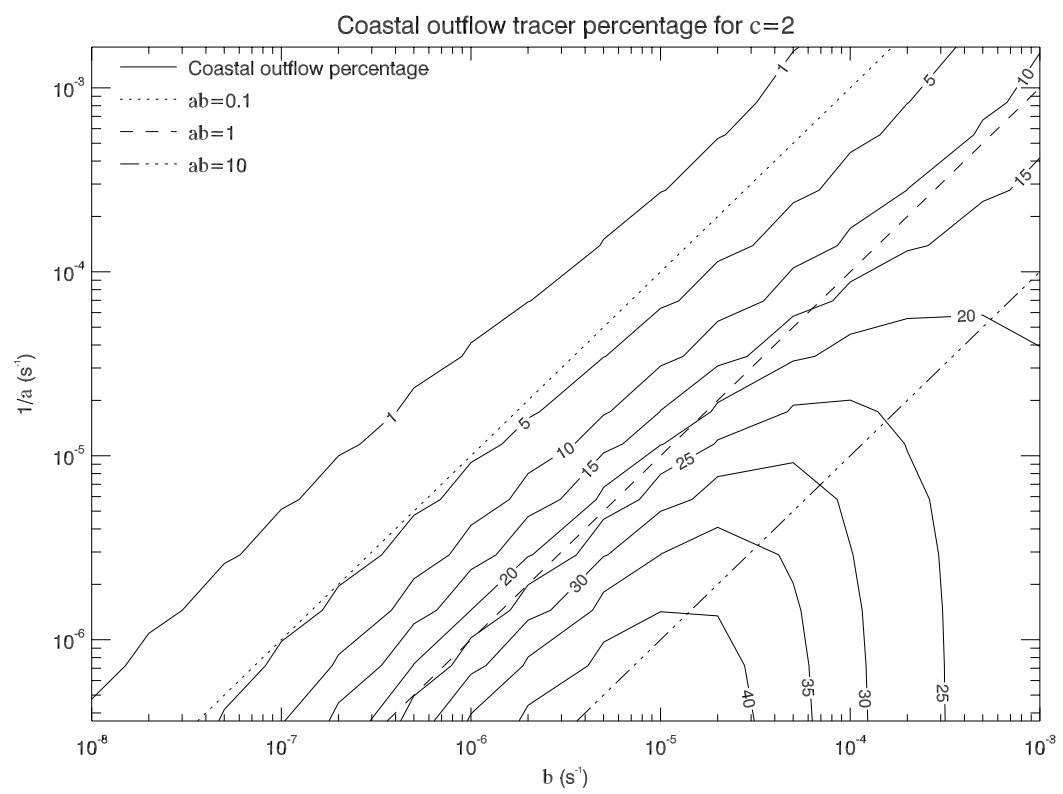

Figure 7: For $c=M A X C B L / M B L=2$, the dependence of average daily proportion of tracer exported by coastal outflow on tracer lifetime $a$ and wind speed to landwidth ratio $U / L$. Short lived tracers are represented by $\mathrm{ab}<0.1$ (dotted line), and long lived tracers are represented by $a b>10$ (dash dotted line)

day by coastal outflow and how it varies with tracer lifetime, $a$, and wind speed to landwidth ratio, $b=U / L$, for the case of maximum convective boundary layer height equal to twice the marine boundary layer height $(c=$ $M A X C B L / M B L=2$ ). Figure 6 shows that as tracer lifetime is increased, that the proportion of tracer exported by coastal outflow also increases. This occurs as it can reach the coastline from further inland. As the windspeed is increased, the proportion of exported tracer increases until the timescale of advection across the coast is shorter than the diurnal timescale of boundary layer height. Tracer is advected across the coast before it is able to be mixed above the top of the marine boundary layer, leading to an increase in tracer in the MBL and a decrease in the coastal outflow layer. Increasing windspeed leads to a decrease in coastal outflow for tracers that are long lived with respect to the wind speed $a b>10$, i.e. when the windspeed $U$ exceeds $10 \mathrm{~L} / \mathrm{a}$, equivalent to a $1.16 \mathrm{~ms}^{-1}$ for $L=10 \mathrm{~km}$ and $a=86400 \mathrm{~s}$. Increasing the boundary layer height ratio $c$ also leads to increasing coastal outflow at all lifetimes and windspeeds, but as already noted this is not the meteorologically dominant factor in controlling coastal outflow. 


\section{Conclusions}

Modelling over the eastern US coast using passive tracers within the UM has shown that the magnitude of ventilation of pollutants by coastal outflow, the export of pollutants from a layer within the continental boundary layer to a layer above the marine boundary layer, occurs on a similar order to ventilation by convection. Due to the diurnal boundary layer height cycle over land, a diurnal cycle is induced in export by coastal outflow. For tracers with modelled 3-hour and 24-hour half lives, $5 \%$ and $12 \%$ of total tracer emitted over land is exported by coastal outflow. The 3-hour tracer exhibits strong diurnal variability with a maximum in the late afternoon (when the greatest amount of tracer has been mixed above the marine boundary layer top) and a minimum in the early morning (when pollutants have remained trapped near the surface by the shallow nocturnal layer). The 24-hour tracer exhibits little diurnal variation but instead is more variable on a day-to-day timescale, and is strongly correlated with the $850 \mathrm{~m}$ zonal wind speed $(850 \mathrm{~m}$ being a typical height at which coastal outflow occurs).

Based on a simple 2D model, the sensitivity of coastal outflow to wind speed, maximum convective boundary layer and pollutant lifetime has been tested. Increasing any of these variables increases coastal outflow, although it has been shown that the maximum convective boundary layer height varies little from dayto-day and does not explain the variability in coastal outflow for a tracer 24hour lifetime during our simulation. Cross-coastal wind-speed is the dominant mechanism controlling the export of pollutants by coastal outflow. There is a threshold $U=10 L / a$, where $U$ is the cross-coastal wind speed, $L$ is the width of land and $a$ is the pollutant half life, above which increasing the wind speed leads to a decrease in coastal outflow due to tracer being advected across the coast before having the chance to be mixed to a height above the marine boundary layer. Convection, while active in the UM simulation, has negligible effect on export by coastal outflow.

\section{References}

[1] Clappier, A., Martilli, A., Grossi, P., Thunis, P., Pasi, F., Krueger, B.C., Calpini, B., Graziani, G. \& van den Bergh, H., Effect of sea breeze on air pollution in the greater Athens area. part i: Numerical simulations and field observations. J Appl Meteorol, 39, pp. 546-562, 2000.

[2] Liang, Q., L., J., Hudman, R.C., Turquety, D.J., S. Jacob, Avery, M.A., Browell, E.V., Sachse, G.W., Blake, D.R., Brune, W., Ren, X., Cohen, R.C., Dibb, J.E., Fried, A., Fuelberg, H., Porter, M., Heikes, B.G., Huey, G., Singh, H.B. \& Wennberg, P.O., Summertime influence of asian pollution in the free troposphere over north America. J Geophys Res, 112(D12S11), 2007.

[3] Agusti-Panareda, A., Gray, S.L. \& Methven, J., Numerical modeling study of boundary layer ventilation by a cold front over Europe. J Geophys Res, 110(D18304), 2005.

[4] Donnell, E.A., Fish, D.J., Dicks, E.M. \& Thorpe, A.J., Mechanisms 
for pollutant transport between the boundary layer and free troposphere. J Geophys Res, 106(D8), 2001.

[5] Sinclair, V.A., Gray, S.L. \& Belcher, S.E., Boundary-layer ventilation by baroclinic life cycles. Q J R Meteorol Soc, 134, pp. 1409-1424, 2008.

[6] Dacre, H.F., Gray, S.L. \& Belcher, S.E., A case study of boundary layer ventilation by convection and coastal processes. J Geophys Res, 112(D17106), 2007.

[7] Verma, S., Boucher, O., Venkataraman, C., Reddy, M.S., Müller, D., Chazette, P. \& Crouzille, B., Aerosol lofting from sea breeze during the Indian ocean experiment. J Geophys Res, 111(D07208), 2006.

[8] Raman, S., Niyogi, D.d.S., Simpson, M. \& Pelon, J., Dynamics of the elevated land plume over the arabian sea and the northern Indian ocean during northeasterly monsoons and during the Indian ocean experiment (indoex). Geophys Res Lett, 29(16), 2002.

[9] Cullen, M.J.P., The unified forecast/climate model. Meteor Mag, 122, pp. 8194, 1993.

[10] Lock, A.P., Brown, A.R., Bush, M.R., Martin, G.M. \& Smith, R.N.B., A new boundary layer mixing scheme. part i: Scheme description and single-column model tests. Mon Wea Rev, 128, pp. 3187-3199, 2000. 